Check for updates

Cite this: Phys. Chem. Chem. Phys., 2018, 20, 11484

DOI: $10.1039 / c 8 c p 90075 b$

\section{Correction: Origin of the temperature dependence of the energy gap in $\mathrm{Cr}$-doped $\mathrm{Bi}_{2} \mathrm{Se}_{3}$}

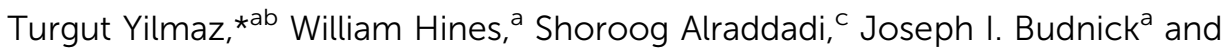 \\ Boris Sinkovic ${ }^{a}$
}

Correction for 'Origin of the temperature dependence of the energy gap in $\mathrm{Cr}$-doped $\mathrm{Bi}_{2} \mathrm{Se}_{3}$ ' by Turgut Yilmaz et al., Phys. Chem. Chem. Phys., 2018, DOI: 10.1039/c7cp08049b.

rsc.li/pccp

The authors would like to make the following corrections to their published article:

(1) On page 8627, left column, sentence beginning "For further confirmation...", the formula $\mathrm{Bi}_{1.84} \mathrm{Cr}_{0.16} \mathrm{Se}_{3}$ should be replaced with $\mathrm{Bi}_{1.78} \mathrm{Cr}_{0.22} \mathrm{Se}_{3}$ so that the amended sentence reads "For further confirmation, we simulate the electron doping effect by growing extra $\mathrm{Cr}$ metal on the surface of $\mathrm{Bi}_{1.78} \mathrm{Cr}_{0.22} \mathrm{Se}_{3}$ (Fig. 6)."

(2) In Fig. $4, \mathrm{Bi}_{2} \mathrm{Se}_{3}$ should be replaced with $\mathrm{Bi}_{1.84} \mathrm{Cr}_{0.16} \mathrm{Se}_{3}$ as shown in the amended figure below:

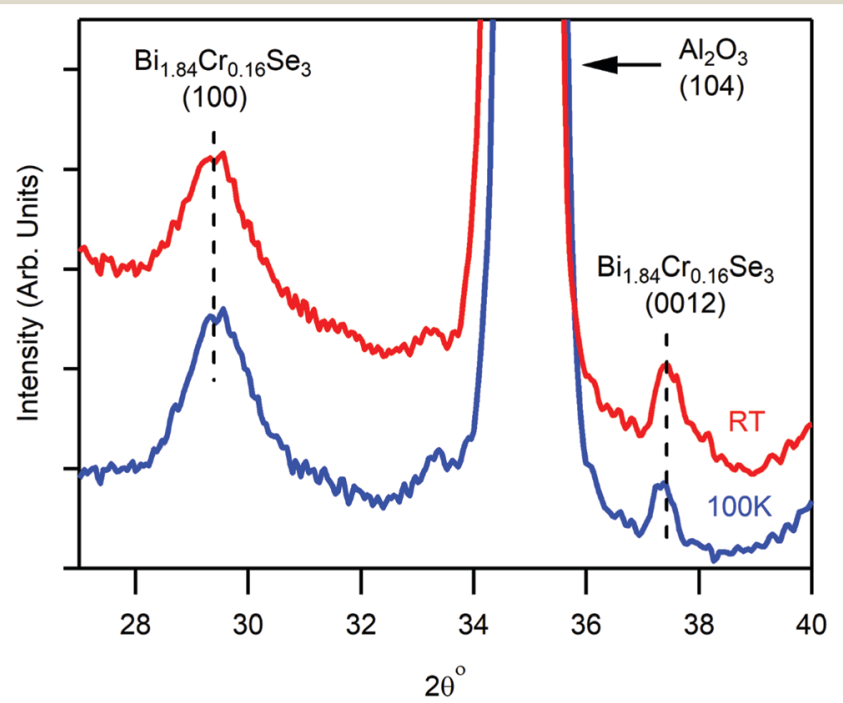

Fig. 4 X-ray diffraction patterns obtained RT (red) and $100 \mathrm{~K}$ (blue) for $\mathrm{Bi}_{1.84} \mathrm{Cr}_{0.16} \mathrm{Se}_{3}$ films grown on $\mathrm{Al}_{2} \mathrm{O}_{3}(0001)$ substrates. Data were collected with Cu K $\alpha$ radiation $(\lambda=1.5418 \AA$ ). Dashed lines are for guiding the eyes.

The Royal Society of Chemistry apologises for these errors and any consequent inconvenience to authors and readers.

\footnotetext{
${ }^{a}$ Department of Physics, University of Connecticut, Storrs, Connecticut 06269, USA. E-mail: yilmaz@phys.uconn.edu

${ }^{b}$ Department of Physics, Science and Literature Faculty, Uludag University, Bursa 16059, Turkey. E-mail: turgutyilmaz@uludag.edu.tr

${ }^{c}$ Department of Physics, Umm Al-Qura University, Makkah 24382, Kingdom of Saudi Arabia
} 